\title{
A HABITAÇÃO PARA A POPULAÇÃO DE BAIXA RENDA NO BRASIL: TERMOS E CONCEITOS DIFUNDIDOS PELA POLÍTICA NACIONAL DE HABITAÇÃO
}

\author{
Alexsandro Tenório Porangaba* \\ *Universidade Federal de Sergipe, Departamento de Engenharia Civil, Aracaju, SE, Brasil.
}

\begin{abstract}
Resumo
Em âmbito nacional, é possivel fazer uso de um termo e de um conceito generalistas que caracterizem e definam qualquer habitação produzida pela e para a população de baixa renda no Brasil? Na intenção de responder a esse questionamento, este artigo apresenta o resultado das análises desenvolvidas nos documentos oficiais referentes à Política Nacional de Habitação, instituída no país em 1946. O objetivo foi identificar termos e conceitos empregados pelo Governo Federal para caracterizar e definir a habitação da população de baixa renda no país. O percurso histórico aqui elucidado evidenciou que os termos "Habitação Popular" e "Habitação de Interesse Social" foram os mais citados nos documentos oficiais nacionais. Entretanto, apesar das semelhanças, esses termos possuem conceitos distintos, que foram reformulados ao longo dos anos de modo a se adaptarem aos interesses da Política Nacional de Habitação e à situação socioeconômica do país.

Palavras-chave

Habitação Popular; Habitação de Interesse Social; Política Nacional de Habitação.
\end{abstract}




\title{
HOUSING FOR THE LOW-INCOME POPULATION IN BRAZIL: TERMS AND CONCEPTS DISSEMINATED BY THE NATIONAL HOUSING POLICY
}

\author{
Alexsandro Tenório Porangaba* \\ *Universidade Federal de Sergipe, Departamento de Engenharia Civil, Aracaju, SE, Brazil.
}

\begin{abstract}
At the national level, is it possible to make use of a generalist term and concept that characterize and define any housing produced by and for the low-income population in Brazil? In order to answer this question, this article presents the results of analyzes developed in the official documents referring to the National Housing Policy, instituted in the country in 1946. The objective was to identify terms and concepts used by the Federal Government to characterize and define the housing of the low-income population in the country. The historical path elucidated here showed that the terms "Popular Housing" and "Social Interest Housing" were the most cited in official national documents. However, despite the similarities, the terms have different concepts, which have been reformulated over the years in order to adapt to the interests of the National Housing Policy and the country's socioeconomic situation.
\end{abstract}

Keywords

Popular Housing; Social Interest Housing; National Housing Policy. 


\section{A HABITAÇÃO PARA A POPULAÇÃO DE BAIXA RENDA NO BRASIL: TERMOS E CONCEITOS DIFUNDIDOS PELA POLÍTICA NACIONAL DE HABITAÇÃO}

Alexsandro Tenório Porangaba

Introdução

O problema habitacional vivido pela população de baixa renda no Brasil tem sido tema recorrente de debate entre políticos, movimentos sociais organizados e distintas categorias profissionais em encontros nacionais. Os primeiros encontros constituídos para o debate exclusivo do problema nacional de habitação coincidem com o período de desenvolvimento urbano-industrial então nascente no país e com os problemas decorrentes do intenso êxodo rural e do crescimento populacional a partir de 1930.

Naquele período, motivados pelo projeto nacional desenvolvimentista de Getúlio Vargas, engenheiros-arquitetos, engenheiros civis, entre outras categorias profissionais, “[...] acompanhados de preceitos morais e higiênicos” (CARPINTÉRO, 1997, p. 108), passam a discutir o problema da habitação pelo aspecto econômico e técnico a ponto de adotarem e difundirem o termo Habitação Econômica para caracterizar e identificar a habitação da população de baixa renda², especialmente

1. Este artigo é fruto da tese de doutorado do autor, intitulada O lugar da Habitação de Interesse Social no ensino de Arquitetura e Urbanismo no Brasil: uma análise curricular (1930-2018), desenvolvida no Programa de Pós-graduação em Arquitetura e Urbanismo da Universidade Federal da Bahia e concluída em 2019, com orientação da Prof ${ }^{a}$. Dra. Naia Alban Suarez e do Prof. Dr. Nivaldo Vieira de Andrade Junior.

2. Neste artigo, não será estabelecida uma definição estanque sobre "população de baixa renda" devido ao fato de essa classificação ter passado por reformulações periódicas na história da Política Nacional de Habitação. 
no $1^{\circ}$ Congresso de Habitação (em 1931) e na Jornada de Habitação Econômica (em 1941).

Segundo evidenciado nos trabalhos de Bonduki (2017), Bruna (2015) e Carpintéro (1997), a habitação econômica não era apenas aquela onde prevalecia a redução de custos de construção e de dimensões dos cômodos; seu entendimento englobava, ainda, a ideia de moralidade e civilidade. Essa perspectiva pode ser constatada na fala do engenheiro Marcelo Taylor C. Mendonça, ao afirmar, no $1^{\circ}$ Congresso de Habitação, que a população de baixa renda não estava preparada para residir em habitações econômicas coletivas, pois essas exigiam "[...] certa educação hygienica [e] harmonia entre seus moradores, [...] coisa que difficilmente se obtém entre pessoas ainda mal iniciadas na vida moderna e que só se poderá conseguir depois de um certo grao de civilização” (MENDONÇA, 1931, apud CARPINTÉRO, 1997, p. 131)3. Não por acaso, os “ideólogos da casa própria unifamiliar”4 (BONDUKI, 2017, p. 93) consideravam esse tipo de casa como a mais apropriada para o desenvolvimento da família conservadora brasileira e, portanto, ideal para moralizar o comportamento da população de baixa renda, especialmente os residentes em habitações coletivas.

Diante da situação socioeconômica do país e da demanda crescente de habitações nos grandes centros urbanos, os congressistas do $1^{\circ}$ Congresso de Habitação recomendaram a criação de um órgão governamental específico que pudesse viabilizar, nacionalmente, a produção seriada de habitações econômicas (CARPINTÉRO, 1997). No entanto, em face da inexistência desse órgão e de um sistema de financiamento para a aquisição da casa própria, muitas famílias submetiam-se a viver em habitações produzidas para o mercado de locação, cujas condições de habitabilidade estavam diretamente vinculadas ao valor cobrado pelo proprietário.

A produção de habitações de aluguel contribuiu para a constituição de distintas modalidades de moradias e, além disso, favoreceu a difusão social de termos que eram utilizados para identificar as habitações ocupadas pela população de baixa renda, tais como cortiço; hotel-cortiço; casa de cômodos (sobrados convertidos em cortiços); cortiço-pátio; casa operária; cabeças de porco (quartos individuais, com cozinha e banheiro comuns); vilas higiênicas e vilas operárias. Somam-se a esses outros termos legitimados em decretos estaduais e municipais de

3. Na citação, optou-se por manter a ortografia original..

4. Bonduki nomeia como "ideólogos da casa própria unifamiliar" os autores Armando Sinisgalli, Francisco de Paula Ferreira e Hélio Arruda, que teceram comentários sobre os modos de morar em habitações coletivas e apontaram os problemas que elas acarretavam para o desenvolvimento da família conservadora. 
distintas regiões do país, a exemplo de habitação das classes pobres, legitimado no Decreto $\mathrm{n}^{\circ} 233$, de 2 de março de 1894, do estado de São Paulo; habitações proletárias de tipo econômico, habitações de tipo mínimo (voltadas para a população removida de favelas) e habitações anti-higiênicas, todos legitimados no Decreto $\mathrm{n}^{\circ} 6.000$, de 1 de julho de 1937, do Distrito Federal/Rio de Janeiro; mocambo ${ }^{5}$ (tipo de habitação construída com palha, sapê ou taipa) e casebre, legitimados no Decreto-Lei Municipal no 347, de 6 de outubro de 1944, do município de Salvador, Bahia.

Há também os termos atribuídos às habitações construídas em ocupações irregulares, como é o caso das palafitas, edificadas em regiões alagadiças (como as das margens dos igarapés, em Manaus, e do rio Capibaribe, em Recife) e os denominados barracos ou casas de lona (encontrados, por exemplo, em Maceió, Alagoas).

Diante da variedade terminológica utilizada para identificar e caracterizar a habitação ocupada pela população de baixa renda, sobretudo num país de dimensões continentais como o Brasil, questiona-se: em âmbito nacional, é possível fazer uso de um termo e de um conceito generalistas que caracterizem e definam qualquer habitação produzida pela e para a população de baixa renda? Na intenção de responder a esse questionamento, este artigo apresenta as análises desenvolvidas nos documentos oficiais - leis, decretos, resoluções, medidas provisórias etc. - referentes à Política Nacional de Habitação, instituída no Brasil a partir de 1946. O objetivo foi identificar termos e conceitos utilizados pelo Governo Federal para caracterizar e definir a habitação produzida pela e para a população de baixa renda. O resultado foi organizado em três partes: na primeira, apresentam-se as análises dos documentos da Fundação da Casa Popular (FCP), instituída em 1946; a segunda refere-se às análises dos documentos do Banco Nacional de Habitação (BNH), criado em 1964; na terceira parte, são apresentadas as análises dos documentos oficiais dos programas nacionais de habitação, instituídos entre 1985 e 2020; e por fim, são realizadas as considerações finais.

\section{A oficialização nacional do termo Habitação Popular em 1946}

Antes de comentar sobre a institucionalização da primeira Política Nacional de Habitação em 1946, é importante entender, brevemente, o cenário da produção habitacional brasileira que antecedeu essa institucionalização, em especial a partir de 1930, quando Getúlio Vargas assume o comando do país. Após ter decretado o

5. Em 12 de julho de 1938, foi fundada em Pernambuco a Liga Social contra o Mocambo com a finalidade de extinguir esse tipo de habitação no estado. A Liga funcionou até 1945 e em seu lugar foi criado o Serviço Social contra o Mocambo, sediado em Recife, por meio do Decreto-Lei $\mathrm{n}^{\circ}{ }^{1.118}$, de 15 de fevereiro de 1945. 
Governo Provisório ${ }^{6}$, Vargas põe em ação seu plano de desenvolvimento e passa a intervir em todos os aspectos econômicos, inclusive na produção habitacional direcionada à classe trabalhadora de média e baixa renda.

A primeira ação do Governo Provisório em relação à produção habitacional foi a aprovação do Decreto $\mathrm{n}^{\circ}$ 19.496, de 17 de dezembro de 1930, facultando a aplicação de fundos das Caixas de Aposentadoria e Pensões, instrumento criado em 1923, para a construção de casas destinadas aos operários e funcionários da União. Já em 1931, com a aprovação do Decreto $n^{\circ}$ 19.646, de 30 de janeiro, o governo autoriza a aplicação de parte dos fundos do Instituto de Previdência dos Funcionários Públicos da União à construção e aquisição de casas para os funcionários públicos. De imediato, essas ações se limitaram a um grupo restrito da população brasileira, mas, diante da demanda crescente de habitações e da intensificação das favelas e loteamentos clandestinos, era importante que Vargas pudesse desenvolver estratégias de ação que beneficiassem a população de baixa renda em geral, sobretudo com a criação de um órgão público que fosse responsável pela produção habitacional no país.

Efetivamente, Getúlio Vargas não oficializou a criação do referido órgão público, de modo que a alternativa encontrada foi autorizar os Institutos de Aposentadorias e Pensões (IAPs), criados entre 1933 e 19387, a desempenhar, entre outras, a função de agente produtor de habitações. Com a aprovação do Decreto $n^{0} 1.749$, de 28 de junho de 1937, que regulamentou a aquisição de prédios destinados à moradia dos associados, os IAPs iniciam uma trajetória de produção habitacional e assumem “[...] papel fundamental na expansão do capitalismo e da industrialização do Brasil [...]” (BONDUKI, 2017, p. 111).

Apesar da importância histórica dos IAPs na produção de habitações, salienta-se que a atuação deles não fazia parte de uma Política Nacional de Habitação, especialmente por não se tratar da principal atividade dos Institutos. Além disso, o incentivo à produção habitacional de Vargas beneficiou apenas os trabalhadores associados, enquanto os informais (aqueles que não possuíam carteira assinada), os desempregados e os trabalhadores da zona rural continuaram à margem das ações governamentais, muitos dos quais sem condições de acesso à habitação.

A primeira Política Nacional de Habitação só foi oficializada no governo do general Eurico Gaspar Dutra (1946-1951), com a criação do primeiro órgão federal

\footnotetext{
6. Decreto $\mathrm{n}^{0}$ 19.398, de 11 de novembro de 1930.

7. Nesse período o governo brasileiro criou seis IAPs divididos por categorias profissionais: Marítimos; Bancários; Comerciários; Industriários; Empregados em Transportes e Cargas; e Estivadores.
} 
responsável especificamente pela área da habitação e desenvolvimento urbano no país, a Fundação da Casa Popular (FCP), instituída por meio do Decreto-Lei nº 9.218, de $1^{\circ}$ de maio de 1946.

Foi com a criação da FCP que o Governo Federal oficializou o termo Casa Popular $^{8}$ para identificar toda habitação direcionada à população de baixa renda (com ou sem emprego fixo), produzida ou subsidiada pela FCP e localizada em centros urbanos ou rurais. Destaca-se ainda que, no referido Decreto-lei, o Governo Federal também faz uso das palavras "moradia”, "residência” e "habitação" como substitutos da palavra "casa”; assim, era possível a utilização dos termos Moradia Popular, Residência Popular e Habitação Popular.

Inicialmente, o conceito atribuído a esses termos não contemplava aspectos condizentes aos serviços de saneamento, abastecimento de água, localização das habitações, etc. Isso só ocorreu após a aprovação do Decreto-Lei ${ }^{\circ}$ 9.777, de 6 de setembro de 1946, que estabeleceu bases financeiras para a FCP e possibilitou, por intermédio dela, o financiamento de obras de infraestrutura urbana e outras capazes de promover a melhoria das condições de vida e bem-estar da população atendida, o que impactaria na qualidade da habitação.

Todo esse desenho institucional, expresso nos documentos oficiais nacionais, faria da FCP "um verdadeiro órgão de política urbana lato sensu" do país (AZEVEDO; ANDRADE, 2011, p. 8). Porém, seu desempenho na produção habitacional não ocorreu como idealizado, visto que vários setores da sociedade, além dos profissionais ligados ao mercado da construção civil, por interesses corporativos, políticos ou econômicos, não apoiaram o Governo Federal nem a FCP.

No aspecto quantitativo, por não possuir fonte garantida de recursos financeiros, a FCP só conseguiu produzir 18.127 unidades habitacionais (FINEP/GAP, 1985) durante seus dezoito anos de existência. No entanto, desse quantitativo, poucas foram as unidades que chegaram a ser ocupadas por trabalhadores de menor poder aquisitivo. Segundo Azevedo (1988, p. 108), o processo de seleção dos trabalhadores para aquisição de habitações populares pela FCP “[...] foi distorcido, favorecendo aqueles que possuíam 'pistolão' político [...]”. Ademais, destaca-se que os termos Casa Popular e Habitação Popular foram os que se popularizaram na sociedade brasileira, em instituições públicas estaduais e municipais ${ }^{9}$, e entre os distintos

\footnotetext{
8. O termo não é uma novidade da FCP. Ele já havia sido utilizado em leis municiais e decretos federais entre o início do século XX e o fim da República Velha, a exemplo da Lei n 1.330, de 16 de junho de 1916, e do Decreto $\mathrm{n}^{\circ}$ 14.813, de 20 de maio de 1921. Mas, com a FCP, o termo foi oficializado numa Política Nacional de Habitação.

9. Por exemplo, o termo aparece nas seguintes situações: no Paraná, em 1950, foi criada a Caixa de Habitação Popular/CHPEP; em Porto Alegre, no ano de 1951, foi criado o Serviço de Habitação Popular; em 1952, Caxias do Sul, no Rio Grande do Sul, cria o Fundo Especial para a Casa Popular; em 1961, na Paraíba, é criada a Companhia Estadual de Habitação Popular/CEHAP etc.
} 
profissionais envolvidos com a questão da habitação, mas, em 1964, eles foram inicialmente substituídos nos documentos oficiais da nova Política Nacional de Habitação, como será evidenciado no item subsequente.

\section{A criação do termo Habitação de Interesse Social e a reformulação do} conceito de Habitação Popular na Ditadura Militar

A partir de 1963, o presidente João Goulart buscou efetivar importantes reformas de base e ampliar o voto, estendendo-o aos analfabetos. Suas intenções provocaram reações opostas na sociedade brasileira: por um lado, os setores de esquerda, grupos nacionalistas e líderes trabalhistas identificaram-se com tais propostas e declararam seu apoio ao presidente; por outro, elas causaram incômodo nas elites empresariais e militares (COSTA, 2016). Os opositores passaram a conspirar contra o governo e, em $1^{\circ}$ de abril de 1964, o então presidente do Senado Federal, Auro de Moura Andrade, decretou a vacância de João Goulart da presidência e deu início ao período político ditatorial no país, encabeçado pelo militar Humberto de Alencar Castelo Branco.

Quatro meses após tomar o poder, Castelo Branco aprova a Lei $\mathrm{n}^{0} 4.380$, de 21 de agosto de 1964, que corporificou o Plano Nacional de Habitação como resultado da institucionalização do Sistema Financeiro da Habitação (SFH). Além disso, criou o BNH e transformou a FCP em Serviço Federal de Habitação e Urbanismo.

Com a aprovação dessa lei, a habitação destinada à população de baixa renda deixa de ser denominada oficialmente Habitação Popular e passa a se chamar Habitação de Interesse Social, como evidenciado no artigo $1^{0}$ :

O Governo Federal, através do Ministro de Planejamento, formulará a política nacional de habitação e de planejamento territorial, coordenando a ação dos órgãos públicos e orientando a iniciativa privada no sentido de estimular a construção de habitações de interesse social e o financiamento da aquisição da casa própria, especialmente pelas classes da população de menor renda (BRASIL, 1964, p. 1, grifos nossos).

Não há na história da política habitacional do Brasil registros oficiais que demonstrem as razões de o governo ditatorial adotar o termo Habitação de Interesse Social, mas alguns fatos sinalizam possíveis motivações para essa mudança terminológica. Quando a FCP foi instituída, o Governo Federal, na intenção de ampliar as possibilidades de financiamento para a compra ou a construção da casa própria, acabou por não definir com clareza as condições mínimas exigidas para que os futuros interessados fossem considerados aptos à concessão financeira. $\mathrm{O}$ artigo $6^{\circ}$ do Decreto-Lei $n^{\circ}$ 9.218, de $1^{\circ}$ de maio de 1946, especifica apenas que a preferência 
para aquisição ou construção de moradia estabelecida entre os candidatos deveria obedecer à seguinte proporção: a) trabalhadores em atividades particulares - 3; b) servidores públicos ou de autarquias - 1; c) outras pessoas - 1 (BRASIL, 1946).

Com base no que foi estabelecido no citado decreto-lei, por não ter sido especificada uma renda mínima ou máxima, uma interpretação possível era a de que qualquer pessoa, com ou sem rendimentos fixos, poderia ser beneficiada com o financiamento habitacional. Devido às distorções na interpretação do Decreto-Lei $n^{\circ}$ 9.218, o Governo Federal, em 1951, decide estabelecer um parâmetro financeiro máximo para os candidatos à aquisição ou construção de uma habitação popular pela FCP. Assim, segundo o texto da Lei $n^{0}$ 1.473, de 24 de novembro de 1951, os interessados não poderiam apresentar "renda global líquida superior a Cr\$ $60.000,00^{10}$ (sessenta mil cruzeiros)" e deveriam ter "no mínimo cinco pessoas sob a sua dependência econômica” (BRASIL, 1951, p. 1). Com o estabelecimento da renda global máxima, considerada elevada para o período, a nova legislação legitimou a possibilidade de que "[...] setores relativamente bem aquinhoados pudessem também disputar as almejadas casas populares” (AZEVEDO; ANDRADE, 2011, p. 10).

Todavia, a aquisição de financiamento junto a FCP por parte de famílias de classe média só não ocorreu com maior volume em virtude do fato de a habitação popular ter sido considerada por esses grupos como sinônimo de pobreza (AZEVEDO; ANDRADE, 2011), ou seja, o referido termo carregava um sentido pejorativo, que potencializava visões preconceituosas. Diante desse contexto, os envolvidos com a edição da lei que instituiu o BNH, com o propósito de atrair a adesão da população de classe média ao novo programa, adotam o termo Habitação de Interesse Social na tentativa de eliminar qualquer vestígio de preconceito associado às habitações que seriam produzidas.

Esse ato foi reforçado ainda pela real motivação da institucionalização do BNH. A intenção de fazer com que a nova política habitacional contribuísse para a "estabilidade social" e para a constituição de "aliados da ordem" (AZEVEDO; ANDRADE, 2011, p. 41) encobria um objetivo maior: estimular o crescimento do mercado de trabalho com a geração de novos postos de empregos valendo-se da ação vigorosa da construção civil e dinamizar o setor econômico do país, que, para tanto, também dependia do interesse da classe média pelas habitações produzidas pelo BNH. Com o passar dos anos, esse objetivo maior foi se concreti-

10. Um mês após a publicação da Lei $n^{0} 1.473$ de 1951, o Governo Federal aprova o aumento do salário mínimo para o ano de 1952 no valor de $\mathrm{Cr} \$ 1.200,00$ (mil e duzentos cruzeiros) - Decreto $\mathrm{n}^{\circ} 30.342$, de 24 de dezembro de 1951. Assim, a renda total líquida deveria ser de 50 salários mínimos anuais ou 4,16 salários mínimos mensais. 
zando, o que, por conseguinte, provocou a perda gradual do caráter social do programa habitacional e político (AZEVEDO; ANDRADE, 2011).

A lei que instituiu o BNH possibilitou igualmente respaldo jurídico para a criação de Companhias de Habitação em distintos estados e municípios do país. Porém, ressalta-se que essas companhias não se constituem em frutos do BNH, nem sequer são mencionadas na Lei ${ }^{\circ} 4.380 / 1964$. Em seu artigo $8^{\circ}$ expressa-se somente que órgãos estaduais e municipais seriam integrados ao SFH para facilitar e promover a construção e a aquisição das habitações pela população de baixa renda (BRASIL, 1964), mas isso só foi oficializado em 1966.

Uma das primeiras Companhias de Habitação criadas no Brasil foi instituída em 1962, por meio da Lei ${ }^{\circ}$ 263, de 29 de dezembro, no estado da Guanabara, atual Rio de Janeiro, e foi oficialmente denominada Companhia de Habitação Popular do Estado da Guanabara (COHAB/GB). A utilização de Habitação Popular no nome do órgão se deve à popularização do termo pela FCP e, com o passar dos anos, mesmo depois da instauração da Ditadura Militar, alguns estados constituíram companhias próprias, ora se apropriando do referido termo, ora o abolindo. Alguns exemplos são dados, entre tantas outras, pela Companhia de Habitação Popular de Campina Grande/COHAB-CG (criada pela Lei $n^{0}$ 256, de 14 de dezembro de 1964); pela Companhia de Habitação do Estado do Rio Grande do Sul/COHAB-RS (criada pela Lei ${ }^{\circ}$ 4.892, de 24 de dezembro de 1964), pela Companhia de Habitação do Estado do Pará/COHAB-PA (criada pela Lei no 3.232 , de 13 de abril de 1965).

Assim, se forem consideradas as leis estaduais e municipais, a sigla COHAB pode ter dois significados, Companhia de Habitação ou Companhia de Habitação Popular. Mas, para o Conselho Administrativo do BNH, o termo oficial nacional era apenas “Companhia de Habitação (COHAB)” (BRASIL, 1966, p. 1). Essa denominação foi legitimada em 1966 com a regulação, pelo Conselho Administrativo do BNH, das condições para o registro e a concessão de financiamentos habitacionais dos órgãos estaduais, no caso, as COHABs.

O termo Habitação Popular, inicialmente evitado pela Ditadura Militar, só voltou a ser empregado nos documentos oficiais nacionais em 1973, quando o Conselho Administrativo do BNH, no dia 23 de janeiro, institui o Plano Nacional de Habitação Popular (PLANHAP), o Sistema Financeiro de Habitação Popular e os Fundos Estaduais de Habitação Popular. Com isso, o Governo Federal oficializa em seus documentos a utilização de dois termos: i) Habitação Popular, que passou a ser utilizado para caracterizar e identificar a produção habitacional em série voltada especificamente à "população com renda regular entre um e três salários mínimos regionais” (BRASIL, 1973, p. 1, grifo nosso), com qualidade construtiva e adequada infraestrutura urbana; ii) Habitação de Interesse Social, associado à 
produção habitacional seriada voltada para famílias com renda regular entre três e seis salários mínimos e aquelas com renda superior a seis salários mínimos mensais. Diante dessa distinção terminológica, é importante destacar que as habitações populares (famílias com renda de um a três salários mínimos) eram produzidas pelas COHABs e que as habitações de interesse social, por cooperativas habitacionais - no caso das famílias com renda de três a seis salários mínimos - e por agentes privados (sociedades de crédito imobiliário, associações de poupança e empréstimo) -, no caso de famílias com renda superior a seis salários mínimos (VERAS; BONDUKI, 1986).

Contudo, na prática, as construções efetivadas durante os 22 anos de funcionamento do BNH, serviram para desvirtuar toda a ideia de habitação econômica e habitação popular do período compreendido entre os anos de 1930 e 1963. Além disso, o conceito de habitação de interesse social, assimilado pelo setor da construção civil, se tornou sinônimo do caráter elitista do BNH durante a Ditadura Militar, exatamente por ter se afastado dos financiamentos para a população com renda regular entre um e três salários mínimos (MARICATO, 1987).

\section{Pós-1985: a nova Habitação de Interesse Social}

A Ditadura Militar no Brasil teve seu fim no ano de 1985, quando Tancredo Neves e José Sarney, eleitos de modo indireto por um colégio eleitoral, foram escolhidos para suceder o último militar que presidiu o Brasil no ciclo iniciado em 1964, o general João Baptista Figueiredo (1979-1985). No entanto, Tancredo Neves, em decorrência de complicações de saúde, veio a falecer e quem assumiu a presidência do país foi José Sarney. Este, na medida do possível, seguiu com o processo de abertura política do Brasil, cujo início se deu com o estabelecimento das eleições diretas para presidente, o que só ocorreria em 1989. Destaca-se, ainda, que o governo de José Sarney foi marcado pela instituição da Assembleia Constituinte em 1987 e pela aprovação da nova Constituição Brasileira, em 1988.

No âmbito dos problemas habitacionais, o novo período de redemocratização do país, apesar de ter possibilitado o debate sobre a necessária reforma urbana por movimentos populares organizados, assim como por arquitetos e urbanistas, não foi benéfico o suficiente para a população de baixa renda por conta da ausência de um Plano Nacional de Habitação consistente. Os efeitos da crise do SFH repercutiram nas ações dos governos de José Sarney (1985-1990), Fernando Collor (1990-1992) e Itamar Franco (1992-1995). Todos eles centraram esforços no combate à regularização financeira dos mutuários do SFH e constituíram programas habitacionais de pouco impacto nacional, se comparados com a força produtiva efetivada pelo BNH. 
Em vez de buscar reestruturar a política habitacional por meio do BNH, José Sarney decide extingui-lo em 1986 e incorporar suas funções à Caixa Econômica Federal. A partir de então, a atuação na produção habitacional deixa de ser considerada uma atividade-fim e passa a ser considerada uma atividade-meio e setorial do novo agente responsável pelo SFH. A extinção do BNH caracterizou o fim da política ditatorial de habitação e marcou o início de um novo ciclo na história da produção habitacional brasileira

Até o fim do governo presidencial de Itamar Franco, em 1995, pode-se dizer que houve certa ausência de rumos diretos para os problemas nessa seara. A base de ação no setor direcionado à população de baixa renda ocorre por meio dos chamados "programas alternativos" (AZEVEDO, 2007, p. 16), com destaque para o Programa Nacional de Mutirões Habitacionais, lançado em 1987; o Plano de Ação Imediata para Habitação (PAIH), de 1990, cuja ação se efetivou por meio de três vertentes: i) programa de moradias populares, ii) programa de lotes urbanizados e iii) programa de ação municipal para habitação popular (AZEVEDO, 2007); Programa Habitar-Brasil, datado de 1993; e Programas Morar Melhor e Morar Município, lançados em 1994.

Com base no que foi oficializado nos documentos referentes aos Programas Nacionais de Habitação, evidencia-se que o termo Habitação Popular (mantido após a extinção do BNH e utilizado no PAIH), além de se relacionar com a determinação dos limites de renda familiar, foi utilizado para caracterizar e identificar a produção habitacional efetivada com a participação do poder público - nos âmbitos federal, estadual ou municipal - por meio de subsídio ou produção direta. Esse não é, entretanto, um entendimento consensual entre os profissionais do meio acadêmico, especialmente os da área de arquitetura e urbanismo.

É possível encontrar na literatura especializada o termo Habitação Popular empregado para definir e caracterizar distintos produtos habitacionais, como, por exemplo, na produção de Nabil Bonduki (2017) e na de Maria Alice Junqueira Bastos e Ruth Verde Zein (2010).

Na obra Origens da habitação social no Brasil: arquitetura moderna, lei do inquilinato e difusão da casa própria"11 , nota-se que Bonduki (2017, p. 28) utiliza o termo Habitação Popular para identificar e tipificar toda habitação construída pela e para a população de baixa renda sem a participação ou a intervenção do Governo Federal. Para diferenciar esse tipo de habitação das que eram produzidas com a participação de órgãos estatais, em particular no período de 1940 a 1950, o autor cria um termo novo, Habitação Social. Todavia, esse termo apresenta

11. A obra é oriunda da tese de doutorado de Nabil Bonduki, defendida em 1995. A primeira edição do livro foi publicada em 1998. 
sentido mais amplo, uma vez que não se limita apenas à casa, pois “[...] inclui também a regulamentação estatal da locação habitacional e incorporação, como problema do Estado, da falta de infraestrutura urbana gerada pelo loteamento privado" (BONDUKI, 2017, p. 22). Além disso, em decorrência do contexto político, social, econômico e, sobretudo, de produção habitacional analisado por Bonduki, observa-se que esse termo está diretamente associado ao produto edificado para a população de baixa renda com emprego formal.

Já para Bastos e Zein (2010, p. 163; 303), os termos Habitação Social e Habitação Popular são utilizados de modo generalizado, como se representassem um só conceito e servissem para identificar qualquer tipo de produção habitacional constituída para a população mais pobre, produzida ou não por meio de programas habitacionais. Ademais, destaca-se que o primeiro termo, de acordo com Héctor Vigliecca (2015, p. 3), é considerado um "pleonasmo", visto que, no entendimento desse arquiteto, “[...] toda habitação é social”

Três anos após o lançamento do PAIH, o Governo Federal cria o Programa de Difusão de Tecnologia para a Construção de Habitações de Baixo Custo (PROTECH) e institui um novo termo, Habitação de Baixo Custo (BRASIL, 1993, p. 1). Este caracterizava toda habitação produzida para a população de baixa renda com a utilização de materiais e técnicas construtivas de baixo valor comercial, muito semelhante ao conceito de Habitação Econômica da década de 1930, mas sem o caráter moralizante e civilizatório daquele período

Em 1999, o presidente Fernando Henrique Cardoso, diante da crise econômica estabelecida no país entre os anos de 1998 e 1999 e da queda dos investimentos em habitação, instituiu o Programa de Arrendamento Residencial (PAR) pela Medida Provisória ${ }^{0}$ 1.823, de 29 de abril (BRASIL, 1999), com o objetivo de estimular o mercado da construção civil. Desde o BNH, o país não conseguia emplacar um programa habitacional razoavelmente consistente em nível nacional. Com a institucionalização do PAR, essa abrangência é paulatinamente efetivada em todas as regiões do Brasil

Sobre a adoção de um termo específico para caracterizar a produção habitacional voltada à população de baixa renda, comum nos Programas Nacionais de Habitação, constatou-se que o PAR foi o primeiro a não fazer uso dessa prática. Nos documentos oficiais do programa ${ }^{12}$, não há registro dos termos Habitação Popular, Habitação de Interesse Social ou Habitação de Baixo Custo, nem de outro habilitado a estabelecer alguma relação conceitual com a habitação desse

12. Medida Provisória $\mathrm{n}^{0}$ 1.823, de 29 de abril de 1999; Lei $\mathrm{n}^{\circ}$ 10.188, de 12 de fevereiro de 2001; Lei $\mathrm{n}^{\circ}$ 10.859, de 14 de abril de 2004; Portaria $n^{0}$ 231, de 4 de junho de 2004; Portaria $n^{0} 301$, de 7 de junho de $2006 .$. 
segmento da população. Em vez disso, quando necessário algum tipo de identificação, os documentos fazem uso apenas das expressões "moradia de população de baixa renda" ou "unidade habitacional”.

Para o PAR, inicialmente, a população de baixa renda era aquela cuja renda salarial mensal variasse de três a oito salários mínimos ${ }^{13}$. Após revisões na legislação do programa, já no primeiro mandato presidencial de Luiz Inácio Lula da Silva, a faixa salarial foi ampliada para poder contemplar as famílias com renda de dois a quatro salários mínimos (PORANGABA, 2011).

Em 2004, o extinto Ministério das Cidades ${ }^{14}$ divulga a versão preliminar do novo Plano Nacional de Habitação (PNH) do governo Lula. Nesse documento, a habitação da população de baixa renda volta a ser denominada Habitação de Interesse Social, porém, o conceito a ele atribuído é reformulado mediante o resgate das intenções da política habitacional das décadas de 1940 e 1950.

Segundo a versão preliminar do PNH, o conceito de Habitação de Interesse Social não está restrito a casa; ele "[...] incorpora o direito à infraestrutura, saneamento ambiental, mobilidade e transporte coletivo, equipamentos e serviços urbanos e sociais, buscando garantir direito à cidade" (MINISTÉRIO DAS CIDADES, 2004, p. 12). O elemento inédito nessa ideia de habitação é a preocupação com a cidade, mais precisamente com o fato de a Habitação de Interesse Social ser pensada e produzida de modo integrado.

Objetivamente, o termo Habitação de Interesse Social passou a ser utilizado em referência à produção de habitações viabilizadas por programas habitacionais por meio da ação conjunta ou não entre o Governo Federal, estados e municípios para a população de baixa renda (urbana, rural, indígenas, de povos da floresta, de quilombolas, etc.), entendida como: (1) famílias em situação de miséria absoluta, incapazes de arcar com quaisquer ônus decorrentes de financiamentos onerosos; (2) famílias com renda reduzida, que não dispõem de condições para adquirir uma moradia digna sem o subsídio financeiro proporcionado por política pública (são famílias capazes de pagar parcelas que não onerem seus limites orçamentários de subsistência); (3) famílias cujas capacidades aquisitivas são suficientes para arcar com as parcelas do financiamento de baixo custo, sem subsídio. Em se tratando de parâmetros financeiros, a Habitação de Interesse Social destinava-se, preferencialmente, às famílias com renda mensal de zero até cinco salários mínimos (MINISTÉRIO DAS CIDADES, 2004).

\footnotetext{
13. Em 1999, o salário mínimo era de R \$136,00 (Lei nº 9.971, de 18 de maio de 2000). Portanto, a população de baixa renda definida na legislação do PAR deveria ter renda mensal entre $\mathrm{R} \$$ 408,00 e $\mathrm{R} \$ 1.088$, 00 .

14. O Ministério das Cidades foi extinto pelo presidente Jair Messias Bolsonaro ao assinar a Lei $\mathrm{n}^{0}$ 13.844, de 18 de junho de 2019, e suas atividades foram transferidas para o Ministério do Desenvolvimento Regional.
} 
Com a aprovação da Lei $n^{0}$ 11.888, de 4 de dezembro de 2008 (BRASIL, 2008), mais conhecida como Lei da Assistência Técnica em Habitação de Interesse Social, o termo foi amplamente divulgado e utilizado pelas entidades representativas dos profissionais de arquitetura e urbanismo, em cursos de graduação relacionados com a área e por profissionais liberais da construção civil. No entanto, diferentemente do conceito adotado na versão preliminar do $\mathrm{PNH}$, na lei em foco a Habitação de Interesse Social não se limita apenas à habitação produzida por meio de programas habitacionais, pois passa a ser entendida como qualquer habitação destinada à população com renda mensal de até três salários mínimos, inclusive as produzidas pela iniciativa privada ou autoconstruídas por famílias residentes em áreas urbanas ou rurais.

Em 2009, o Ministério das Cidades e a Secretaria Nacional de Habitação divulgaram a versão final do PNH, e o Governo Federal instituiu os programas Minha Casa, Minha Vida (PMCMV) e Minha Casa, Minha Vida-Entidades, que substituíram o PAR. Com essas ações, foi definido no PNH que Habitação de Interesse Social é todo tipo de habitação unifamiliar ou multifamiliar construída pela e/ou para a população com renda mensal de zero a seis salários mínimos (faixas 1 e 2 do PMCMV) com apoio do Governo Federal (decorrente da produção direta, da liberação de subsídio ou de financiamento). Um dado curioso no PNH diz respeito à utilização, em algumas passagens do documento, do termo Habitação Social. No entanto, observa-se que ele não é empregado com o mesmo sentido desenvolvido por Bonduki em 1995; ao contrário, trata-se de uma expressão simplificada do termo Habitação de Interesse Social. Portanto, pode-se afirmar que Habitação Social não é um termo usado oficialmente pelo Governo Federal para caracterizar e identificar a habitação da população de baixa renda no Brasil, nem é adotado pelo PMCMV.

Para Antunes (2019), o PMCMV se manteve com produção crescente até 2013; de lá para cá, tem estado em escala decrescente de produção. A autora destaca ainda que, de 2015 a 2019, a quantidade anual de unidades habitacionais entregues para a faixa 1 (zero a três salários mínimos) ficou abaixo de 50 mil, e nos anos de 2017 e 2018 nenhuma unidade foi entregue para essa faixa em todo o país.

No dia 25 de agosto de 2020, o presidente Jair Messias Bolsonaro, o ministro da Economia Paulo Guedes e o ministro do Desenvolvimento Regional Rogério Simonetti Marinho assinaram a Medida Provisória $n^{\circ}$ 996, que instituiu o Programa Casa Verde e Amarela ${ }^{15}$, substituto do PMCMV. Com essa medida, o termo Habitação de Interesse Social é submetido a nova reformulação. De acordo com o

\footnotetext{
15. O texto da Medida Provisória $n^{0}$ 996, em vigor até a finalização deste artigo, só poderá ser transformado em lei após ser votado num prazo máximo de 120 dias pela Câmara dos Deputados e pelo Senado Federal, ou seja, até 23 de dezembro de 2020.
} 
exposto no documento oficial, a Habitação de Interesse Social "é entendida em seu sentido amplo de moradia, a qual se integram as dimensões física, urbanística, fundiária, econômica, social, cultural e ambiental do espaço em que a vida do cidadão acontece” (BRASIL, 2020, p. 1). Por fim, segundo o Governo Federal, o termo passa a ser associado a toda produção habitacional direcionada a famílias residentes em áreas urbanas com renda mensal de até $\mathrm{R} \$ 7.000$ (sete mil reais) ${ }^{16}$ divididas por grupos (Quadro 1) e a famílias residentes em áreas rurais, com renda anual de até $\mathrm{R} \$ 84.000,00$ (oitenta e quatro mil reais).

\begin{tabular}{|c|c|c|c|c|c|}
\hline \multicolumn{3}{|c|}{ Programa Minha Casa, Minha Vida } & \multicolumn{3}{|c|}{ Programa Casa Verde e Amarela } \\
\hline Faixa & Faixa de renda & $\begin{array}{l}\text { Modalidade de } \\
\text { atendimento }\end{array}$ & Grupo & Faixa de renda & $\begin{array}{l}\text { Modalidade de } \\
\text { atendimento }\end{array}$ \\
\hline 1 & Até $\mathrm{R} \$ 1.800$ & $\begin{array}{l}\text { Produção } \\
\text { subsidiada }\end{array}$ & \multirow{4}{*}{1} & \multirow{4}{*}{ Até $\mathrm{R} \$ 2.000$} & Produção subsidiada \\
\hline \multirow{3}{*}{1,5} & \multirow{3}{*}{ Até $\mathrm{R} \$ 2.600$} & \multirow{5}{*}{$\begin{array}{l}\text { Produção } \\
\text { financiada }\end{array}$} & & & Regularização fundiária \\
\hline & & & & & $\begin{array}{l}\text { Melhoria habitacional e } \\
\text { regularização fundiária }\end{array}$ \\
\hline & & & & & Produção financiada \\
\hline 2 & Até $\mathrm{R} \$ 4.000$ & & 2 & $\mathrm{R} \$ 2.000$ a $\mathrm{R} \$ 4.000$ & Produção financiada \\
\hline 3 & $R \$ 4.000$ a $R \$ 7.000$ & & 3 & $\mathrm{R} \$ 4.000$ a $\mathrm{R} \$ 7.000$ & $\begin{array}{l}\text { Regularização fundiária } \\
\text { (até } \mathrm{R} \$ 5.000 \text { ) }\end{array}$ \\
\hline
\end{tabular}

Quadro 1. Faixas e grupos de renda dos programas Minha Casa, Minha Vida e Casa Verde e Amarela Fonte: Adaptado do Ministério do Desenvolvimento Regional. ${ }^{17}$

\section{Considerações finais}

Como evidenciado ao longo deste trabalho, o Governo Federal, no processo de formulação e de implementação das Políticas Nacionais de Habitação, tem buscado uniformizar termos e conceitos que possam ser utilizados para identificar e caracterizar a habitação produzida pela e para a população de baixa renda no Brasil.

O percurso histórico-político aqui elucidado demonstrou que, de 1946 a 2020, foram oficializados nas Políticas Nacionais de Habitação três termos: Habitação Popular (em 1946), Habitação de Interesse Social (em 1964) e Habitação de Baixo

16. Considerando que em 2020 o valor do salário mínimo foi de $\mathrm{R} \$ 1.045,00$ (Lei $\mathrm{n}^{\circ}$ 14.013, de 10 de junho de 2020), para o Programa Casa Verde e Amarela, a população de baixa renda é a que recebe mensalmente o valor de o (zero) a 6,7 (seis vírgula sete) salários mínimos, aproximadamente.

17. BRASIL. Ministério do Desenvolvimento Regional. 28 ago. 2020. Disponível em: https://www.gov. $\mathrm{br} / \mathrm{mdr} / \mathrm{pt}$-br/assuntos/habitacao/casa-verde-e-amarela/saiba-o-que-muda-com-o-novo-programa. Acesso em: 30 ago. 2020. 
Custo (em 1993). Desses, os dois primeiros são os mais frequentes nos documentos oficiais nacionais, apesar de os conceitos a eles atribuídos não seguirem uma ordem padronizada, ou seja, a depender dos interesses políticos e da situação socioeconômica do país, elementos foram adicionados ou excluídos dos conceitos.

\section{Referências}

ANTUNES, L. Minha casa perto do fim? Programa habitacional popular faz 10 anos com menos dinheiro e sob pressão para mudar nome e regras. UOL, Rio de Janeiro, 24 nov. 2019. p. 1-14.

AZEVEDO, S. Desafios da habitação popular no Brasil: políticas recentes e tendências. In: CARDOSO, A. L. (org.). Habitação social nas metrópoles brasileiras: uma avaliação das políticas habitacionais em Belém, Belo Horizonte, Porto Alegre, Recife, Rio de Janeiro e São Paulo no final do século XX. Porto Alegre: Antac, 2007. cap. 1. p. 12-41. (Coleção HABITARE/FINEP).

AZEVEDO, S. de. Vinte e dois anos de política habitacional (1964-86): criação, trajetória e extinção do BNH. Revista de Administração Pública, Rio de Janeiro, v. 22, n. 4, p. 107-119, 1988.

AZEVEDO, S. de; ANDRADE, L. A. G. de. Habitação e poder: da Fundação da Casa Popular ao Banco Nacional Habitação. Rio de Janeiro: Centro Edelstein de Pesquisas Sociais, 2011.

BASTOS, M. A. J.; ZEIN, R. V. Brasil: arquiteturas após 1950. São Paulo: Perspectiva, 2010.

BONDUKI, N. Origens da habitação social no Brasil: arquitetura moderna, lei do inquilinato e difusão da casa própria. 7. ed. São Paulo: Estação Liberdade: Fapesp, 2017.

BRASIL. Decreto-Lei $n^{\circ}$ 9.218, de $1^{\circ}$ de maio de 1946. Autoriza a instituição da "Fundação da Casa Popular”. Diário Oficial da União: seção 1 [s.l.], p. 6679, 4 maio 1946. (Publicação original).

Lei $\mathrm{n}^{0}$ 1.473, de 24 de novembro de 1951. Dispõe sobre recursos financeiros para a Fundação da Casa Popular, altera a Lei do Sêlo e dá outras providências. Diário Oficial da União: [s.I.]. 24 nov. 1951.

Lei $n^{\circ} 4.380$, de 21 de agosto de 1964. Institui a correção monetária nos contratos imobiliários de interêsse social, o sistema financeiro para aquisição da casa própria, cria o Banco Nacional da Habitação (BNH), e Sociedades de Crédito Imobiliário, as Letras Imobiliárias, o Serviço Federal de Habitação e Urbanismo e dá outras providências. Diário Oficial da União: Brasília (DF), 11 set. 1964.

. Resolução do Conselho de Administração nº 63, de 14 de janeiro de 1966. Regula as condições para registro e concessão de financiamentos das Companhias de Habitação (COHABs). Resolução do Conselho de Administração. Rio de Janeiro: Banco Nacional de Habitação, p. 1, 2 set. 1966. 
BRASIL. Resolução do Conselho de Administração ${ }^{\circ}$ 1, de 30 de janeiro de 1973. Aprova as diretrizes básicas do Plano Nacional da Habitação Popular (PLANHAP), institui o Sistema Financeiro da Habitação Popular (SIFHAP) e autoriza a criação de Fundos Estaduais de Habitação Popular (FUNDHAP). Resolução do Conselho de Administração. Rio de Janeiro: Banco Nacional de Habitação, p. 1-4, 30 jan. 1973.

Decreto de 28 de julho de 1993. Cria o Programa de Difusão de Tecnologia para a Construção de Habitações de Baixo Custo PROTECH. Diário Oficial da União: Brasília, DF, 29 jul. 1993.

Medida Provisória $\mathrm{n}^{\circ}$ 1.823, de 29 de abril de 1999. Cria o Programa de Arrendamento Residencial, institui o arrendamento residencial com opção de compra e dá outras providências. Diário Oficial da União: Brasília, DF, 30 abr. 1999.

Lei $\mathrm{n}^{\circ} 11.888$, de 24 de dezembro de 2008. Assegura às famílias de baixa renda assistência técnica pública e gratuita para o projeto e a construção de habitação de interesse social e altera a Lei no 11.124, de 16 de junho de 2005. Diário Oficial da União: seção 1, Brasília, DF, p. 2, 26 dez. 2008. PL 6981/2006. (Publicação original).

. Medida Provisória ${ }^{\circ}$ 996, de 25 de agosto de 2020. Institui o Programa Casa Verde e Amarela. Diário Oficial da União: seção 1, Brasília, DF, n. 164, p. 1, 26 ago. 2020.

BRUNA, P. J. V. Os primeiros arquitetos modernos: habitação social no Brasil 1930-1950. São Paulo: EDUSP, 2015.

CARPINTÉRO, M. V T. A construção de um sonho: os engenheiros-arquitetos e a formação da política habitacional no Brasil. Campinas: Ed. da Unicamp, 1997.

COSTA, M. A história do Brasil para quem tem pressa. Rio de Janeiro: Valentina, 2016.

FINEP/GAP. Habitação popular: inventário da ação governamental. Rio de Janeiro; São Paulo: Finep/Projeto. 1985.

MARICATO, E. Política habitacional no regime militar: do milagre brasileiro à crise econômica. Petrópolis: Vozes, 1987.

MINISTÉRIO DAS CIDADES. Política Nacional de Habitação. Brasília, DF: Ministério das Cidades, 2004. (Cadernos MCidades Habitação).

PORANGABA, A. T. Ops! cabe ou não cabe?: tipologia e funcionalidade das habitações do PAR em Maceió. 2011. 188 f. Dissertação (Mestrado) - Programa de Pós-graduação em Arquitetura e Urbanismo, Universidade Federal de Alagoas, Maceió, 2011.

VERAS, M. P. B.; BONDUKI, N. G. Política habitacional e a luta pelo direito à habitação. In: COVRE, M. de L. M. (org.). A cidadania que não temos. São Paulo: Brasiliense, 1986. p. 39-72.

VIGLIECCA, Héctor. 70\% dos territórios urbanos na América Latina são locais informais onde 'não há cidade', diz arquiteto uruguaio. [Entrevista cedida a] Lamia Oualalou. Opera Mundi, São Paulo, p. 1-10, $1^{\circ}$ jun. 2015. Disponível em: https://operamundi.uol.com. br/politica-e-economia/40559/70-dos-territorios-urbanos-na-america-latina-sao-locais-informais-onde-nao-ha-cidade-diz-arquiteto-uruguaio. Acesso em: 12 dez. 2019. 


\section{Alexsandro Tenório Porangaba}

Arquiteto e urbanista formado pela Universidade Federal de Alagoas (UFAL). Mestre em Arquitetura e Urbanismo pelo Programa de Pós-graduação em Arquitetura e Urbanismo, pela mesma instituição. Doutor em Arquitetura e Urbanismo pelo Programa de Pós-graduação em Arquitetura e Urbanismo da Universidade Federal da Bahia (UFBA). Professor do Departamento de Engenharia Civil da Universidade Federal de Sergipe (UFS) na área de Expressão Gráfica e Arquitetura.

Email: soualex@hotmail.com

ORCID: 0000-0002-6124-8013

Submissão: 8 de maio de 2020.

Aprovação: 12 de outubro de 2020.

Como citar: PORANGABA, A. T. A habitação para a população de baixa renda no Brasil: termos e conceitos difundidos pela Política Nacional de Habitação. Revista brasileira de estudos urbanos e regionais. v. 22, E202038, 2020. DOI 10.22296/2317-1529.rbeur.202038

Artigo licenciado sob Licença Creative Commons CC BY-NC 4.0.

https://creativecommons.org/licenses/by-nc/4.o/deed.pt_BR 